Palma, CAP, Borges, RP \& Barroqueiro, CH. (2020). Knowledge management and sustainable economy in the Serra do Mar biodiversity project. Research, Society and Development, 9(7): 1-16, e459974214.

\title{
Gestão do conhecimento e economia sustentável no projeto da biodiversidade da Serra do Mar
}

Knowledge management and sustainable economy in the Serra do Mar biodiversity project

Gestión del conocimiento y economía sostenible en el proyecto de biodiversidad de la Sierra del Mar

Recebido: 04/05/2020 | Revisado: 04/05/2020 | Aceito: 13/05/2020 | Publicado: 21/05/2020

\section{Cleia Aparecida Pinheiro Palma}

ORCID: https://orcid.org/0000-0002-2835-7701

Universidade Santa Cecília, Brasil

E-mail: cleiapalma@gmail.com

Roberto Pereira Borges

ORCID: https://orcid.org/0000-0002-5323-9520

Universidade Santa Cecília, Brasil

E-mail: roborges@unisanta.br

Carlos Henriques Barroqueiro

ORCID: https://orcid.org/0000-0002-4100-7941

Instituto Federal de São Paulo, Brasil

E-mail: carbarroqueiro@gmail.com

\section{Resumo}

A Serra do Mar em Cubatão, São Paulo, é cortada por duas estradas de rodagem, Anchieta e Imigrantes, e uma ferrovia, ligando Jundiaí a Santos. À construção da ferrovia Santos-Jundiaí (1867) e Anchieta (1947) acarretou invasão da Serra do Mar e, assim, trazem, até os dias atuais, problemas graves à biodiversidade. O Governo do Estado de São Paulo e a Prefeitura Municipal de Cubatão desenvolveram o projeto de recuperação socioambiental da Serra do Mar que explicita retirada das pessoas dos bairros-Cota e reflorestamento da área. Em face a isso, o objetivo da pesquisa foi analisar a aplicação da Gestão do Conhecimento e Economia Sustentável sobre o projeto de recuperação socioambiental da Serra do Mar para verificar o alcance das metas do Projeto, e propor pontos inovadores para eficácia da sua gestão. Realizou-se o estado da arte do tema, e usou-se à pesquisa exploratória qualitativa e técnica 
focus group com os moradores dos bairros-cota. Os resultados apresentaram que as metas do Projeto estão sendo alcançadas e mantém-se em execução contínua, social está praticamente resolvida e ambiental em fase regenerativa de sua cobertura vegetal. Conclui-se que há necessidade contínua de monitoramento do processo de recuperação socioambiental da área, evitando, assim, assentamentos irregulares que iriam comprometer a recuperação ambiental: vegetal, mananciais e qualidade da água captada no rio Cubatão.

Palavras-chave: Gestão socioambiental; Preservação do meio ambiente; Economia verde.

\section{Abstract}

The Serra do Mar in Cubatão, São Paulo, is crossed by two highways, Anchieta and Imigrantes, and a railroad, connecting Jundiaí to Santos. In the construction of the SantosJundiaí (1867) and Anchieta (1947) railroad led to the invasion of Serra do Mar and, thus, bring, until today, serious problems to biodiversity. The Government of the State of São Paulo and the Municipality of Cubatão developed Serra do Mar socio-environmental recovery project that explains removal of people from the Cota neighborhoods and reforestation of the area. In view of this, the objective of the research was to analyze the application of Knowledge Management and Sustainable Economy on the Serra do Mar socio-environmental recovery project to verify the achievement Project's goals, and to propose innovative points for the effectiveness of its management. The state of the art of the theme was carried out, and qualitative exploratory research and technical focus group was used with the residents of the quota neighborhoods. The results showed that the goals of the Project are being reached and remains in continuous execution, social is practically resolved and the environment is in the regenerative phase of its vegetation cover. It is concluded that there is a continuous need to monitor the process of socio-environmental recovery of the area, thus avoiding irregular settlements that would compromise the environmental recovery: vegetative, water sources and quality of water captured in the Cubatão river.

Keywords: Social and environmental management; Preservation of the environment; Green economy.

\section{Resumen}

La Sierra del Mar en Cubatão, São Paulo, es atravesada por dos carreteras, Anchieta y Imigrantes, y un ferrocarril que conecta Jundiaí con Santos. En la construcción de ferrocarril Santos-Jundiaí (1867) y Anchieta (1947) condujo a la invasión de la Sierra del Mar y, por lo tanto, trae serios problemas a la biodiversidad hasta nuestros días. El Gobierno del Estado de 
São Paulo y la Municipalidad de Cubatão desarrollaron el proyecto para la recuperación social y ambiental de la Sierra del Mar que expulsa explícitamente a las personas de los barrios de Cota y reforesta el área. En vista de esto, el objetivo de la investigación fue analizar la aplicación de la Gestión del Conocimiento y la Economía Sostenible en el proyecto de recuperación social y ambiental de la Sierra del Mar para verificar el logro de los objetivos del Proyecto y proponer puntos innovadores para la efectividad de su gestión. Se llevó a cabo el estado del arte del tema y se utilizó un grupo focal de investigación exploratoria cualitativa y técnica con los residentes de los vecindarios de los barrios cuotas. Los resultados mostraron que los objetivos del Proyecto se están alcanzando y se mantiene en ejecución continua, la sociedad está prácticamente resuelta y el medio ambiente se encuentra en una fase regenerativa de su cubierta vegetal. Se concluye que existe una necesidad continua de monitorear el proceso de recuperación social y ambiental del área, evitando así asentamientos irregulares que comprometerían la recuperación ambiental: vegetación, fuentes de agua y calidad del agua capturada en el río Cubatão.

Palabras clave: Gestión social y ambiental; Preservación ambiental; Economía verde.

\section{Introdução}

A Mata Atlântica tem a maior biodiversidade por metro quadrado do planeta (Almeida; 2016). Do portal do Ministério do Meio Ambiente, o bioma Mata Atlântica original compreendia 1,3 milhões de $\mathrm{km}^{2}$, abrangendo 17 estados do território nacional, estendendo-se por praticamente $29 \%$ de toda a costa brasileira. Desde a colonização ocorre um processo de degradação do meio ambiente. Isso acontece porque a população de nosso país, nos dias atuais, concentra-se, em parte, onde outrora existiu a Mata Atlântica. Devido à degradação que a Mata Atlântica sofreu, torna-se essencial que o restante dela, vinte e nove por cento (29\%), seja preservado com todo o rigor; isto se deve a importância científica (investigação), social (a vida) e ambiental (preservação das espécies).

A partir dos anos 1950, ocorreu intensa ocupação humana do litoral paulista, com implantação do polo industrial em Cubatão e expansão do Porto de Santos acarretaram graves problemas na Biodiversidade da Serra do Mar. As construções da Rodovia Anchieta e, posteriormente, da Rodovia dos Imigrantes proporcionaram, a vinda de milhares de trabalhadores de todo o Brasil para a execução das obras. Com o tempo, no caso da construção da Rodovia Anchieta, cada trabalhador trazia ou constituía sua família, 
transformando os antigos acampamentos construídos pelo Departamento de Estradas de Rodagem (DER) em bairros informais.

Originam-se desse período os bairros-Cota no município de Cubatão, constituídos no meio da Mata Atlântica. A história das origens até a consolidação dos bairros-Cota em Cubatão é marcada por adversidades incontáveis, sobretudo, pelas ameaças de riscos e vulnerabilidades de toda ordem, configurando um quadro de alerta constante. Nesse sentido, quando se consideram a insegurança, exposição a riscos e perturbações provocadas por eventos ou mudanças econômicas, a noção de vulnerabilidade social dá uma visão mais ampla sobre as condições de vida dos grupos sociais mais pobres e, ao mesmo tempo, leva em conta a disponibilidade de recursos e estratégias das próprias famílias para enfrentar os impactos que as afetam (Souto \& Cândido, 2014).

Um conceito possível de ser usado para analisar essas questões é o de vulnerabilidade socioambiental. Definida como a coexistência, cumulatividade ou sobreposição espacial de situações de pobreza/privação social e de situações de exposição a risco e/ou degradação ambiental (Alves, 2013). Esse fenômeno levou o poder público do Estado de São Paulo a iniciar um Projeto de Recuperação Socioambiental da Serra do Mar em Cubatão para deter esse crescente problema.

Embora envolva especificamente o município de Cubatão, há reflexos diretos na cidade de Santos, pois a água consumida pela população da cidade é captada diretamente do Rio Cubatão. A qualidade da água é integralmente afetada, com a presença de moradias irregulares ao longo de seu curso, devido as residências jogarem o esgoto no Rio Cubatão, sem tratamento do esgoto ou saneamento básico ambiental. As ações para solucionar esses problemas urbanos são trabalhadas na Gestão Ambiental Urbana (GAU) que usa a Gestão do Conhecimento e a Economia Sustentável como estratégias para eficácia do projeto de gestão.

A Gestão do Conhecimento tem como um dos princípios fundamentais criar e aplicar novos conhecimentos em inovações com uso da Tecnologia da Informação (Nowacki \& Bachni, 2015), gestão do capital intelectual. O conhecimento é uma ação contínua crescente que se inicia por meio da aquisição e interação das pessoas com a informação (Cantner, Joel \& Schmidt, 2011; Rocha Neto, 2012; Gerami, 2010; Filippini, Güttel \& Nosella, 2012) e potencializa-se por meio das experiências e do desenvolvimento de habilidades e competências. A TI groupware (softwares de apoio a projetos em grupo) tem contribuído para distintas estratégias de Gestão do Conhecimento (Pirkkalainen \& Pawlowski; 2014), entre elas a Gestão Social do Conhecimento (quarta geração) que influencia sobre as políticas públicas em vários campos do saber. 
O objetivo da pesquisa foi analisar a aplicação da Gestão Social do Conhecimento e Economia Sustentável sobre o projeto de recuperação socioambiental da Serra do Mar para verificar o alcance das metas do Projeto, e propor pontos inovadores para eficácia da sua gestão.

Nessa pesquisa utilizou-se a Gestão do Conhecimento para mostrar que o poder público com Tecnologia da Informação e conhecimentos tácitos, explícitos e implícitos dos pesquisadores (Sadeghi \& Rad, 2018; Carayannis, 1999; Luo \& Lee, 2013) tem o dever continuamente de buscar a eficiência socioambiental do Sistema Serra do Mar em Cubatão. A GAU engloba a gestão de um conjunto de atividades técnicas, administrativas, legais e normativas realizadas pelos stakeholders voltadas a melhoria ou conservação da qualidade ambiental da cidade e do seu entorno de influência. Com base na GAU, o governo do Estado de São Paulo elaborou um Plano pela Companhia de Desenvolvimento Habitacional e Urbano (CDHU) para transferência das famílias dos bairros-Cota com propósitos de recuperação ambiental do Bioma da Mata Atlântica e retirá-las das regiões de risco. Em termos de Economia Sustentável, há três conceitos largamente utilizados internacionalmente e em políticas globais: a economia circular (CE), a economia verde (GE) e a bioeconomia (BE). Esses conceitos propõem diferentes soluções para os objetivos da economia, do meio ambiente e da área social (D’amato, Droste, Winkler \& Toppinen, 2019).

A Economia Circular (CE) implica nas ideias de ecologia industrial e metabolismo industrial, isto é, promove a redução e eficiência no uso de recursos materiais na indústria, reuso e reciclagem de produtos industriais, e prolongamento do tempo de vida dos produtos. A Economia Verde (GE) diz que se deve utilizar tecnologia de baixo carbono e eficiência na utilização dos recursos minerais, materiais e insumos, principalmente, água, inteligência. A Bioeconomia (BE) tem como base a troca da indústria fóssil ou complementariedade com recursos e materiais biológicos. Nessa pesquisa baseou-se na GE.

O projeto elaborado pela CDHU necessitou utilizar as estratégias Gestão do Conhecimento e Economia Sustentável, pois foi norteado pelas condições críticas de risco, a importância da recuperação ambiental da Mata Atlântica e o papel social envolvendo as famílias, isto é, conhecimentos tácitos, explícitos e implícitos dos pesquisadores e dos moradores dos Bairros-Cota e a Bioeconomia na região de Mata Atlântica. Priorizou-se o reassentamento das famílias, tendo como base as condições existentes em cada núcleo.

As áreas de Intervenção, no município de Cubatão, foram inicialmente mapeadas para que as famílias fossem reassentadas, para, assim, dar início a recuperação da Mata Atlântica. Conhecimentos específicos foram primordiais nessa etapa para que o plano fosse solidamente 
traçado, além da Tecnologia da Informação. De um total de 7.824 edificações cadastradas, 5.318 foram removidas. O núcleo mais impactado com tais remoções foi o da Cota 200 e este local exigiu uma maior concentração de múltiplos conhecimentos para que o plano começasse a ser executado com sucesso.

Os moradores que permaneceram no local foram contemplados num verdadeiro processo de regularização fundiária, que é um processo de intervenção pública que requer a observação de aspectos jurídicos, físicos e sociais, envolvendo uma equipe multidisciplinar, formada com profissionais das mais diversas áreas, integrando os conhecimentos necessários para a gestão do problema a ser solucionado, por exemplo, foram envolvidos advogados, engenheiros, topógrafos, geólogos, biólogos, assistentes sociais, professores, moradores e formadores (stakeholders). A integração de todos esses conhecimentos foi fundamental para a implantação e execução de todo o projeto de recuperação socioambiental.

No Brasil, os recursos hídricos são protegidos por critérios estabelecidos pela Política Nacional de Recursos Hídricos (PNRH). A PNRH define que a água é um recurso natural limitado e um bem de domínio público, ou seja, a sua utilização deve ser sempre vinculada à função de atender o interesse da coletividade. A PNRH também tem em seus principais objetivos a garantia do uso múltiplo das águas, através da gestão destes recursos que será descentralizada e contará com o apoio do Poder Público, dos usuários e das comunidades (stakeholders). É sabido que ocupações próximas de rios e mananciais geram uma serie de prejuízos à natureza, dentro os quais, a contaminação da água.

No caso em estudo, tem-se um conflito aparente entre direitos fundamentais à moradia e à garantia da Biodiversidade na Serra do Mar, inclusive à qualidade da água do Rio Cubatão, uma vez que é dele que provêm a água distribuída para a cidade de Santos. O clímax do projeto de recuperação socioambiental da Serra do Mar acontecerá quando tanto os problemas sociais quanto os ambientais forem solucionados, de forma a garantir os direitos fundamentais de todos os envolvidos de forma direta e indireta no processo, bem como a recuperação e regeneração das áreas degradas., mantendo-se o equilíbrio do sistema.

\section{Metodologia}

Uma pesquisa busca trazer novos saberes para a sociedade como preconiza Pereira et al. (2018). No presente estudo de natureza qualitativa, realizou-se uma revisão de referências do Estado da Arte do tema que envolve a aplicação da Gestão do Conhecimento e Economia Sustentável como ferramentas estratégicas para analisar e avaliar os efeitos socioambientais 
(CC BY 4.0) | ISSN 2525-3409 | DOI: http://dx.doi.org/10.33448/rsd-v9i7.4214

no processo de transferência das famílias dos bairros-Cota e seus resultados na Recuperação da Biodiversidade do Sistema.

Os conhecimentos utilizados nesta pesquisa são tácitos, explícitos e implícitos, além da Tecnologia da Informação, aplicados na área Social (Gestão Social do Conhecimento). Ainda a investigação preocupou-se com os efeitos ambientais de recuperação total da Mata Atlântica da Serra do Mar, da qualidade da água do Rio Cubatão e das espécies nativas em mangues. Utilizaram-se fotos de satélite por meio do Aplicativo Google Earth e as existentes na literatura para analisar e comparar o andamento de recuperação da área degradada da Serra do Mar e a socialização das famílias. Nessa pesquisa utilizou-se a pesquisa exploratória qualitativa e técnica focus group com os moradores dos bairros-cota. A investigação realizada pela análise indutiva observacional qualitativa e técnica focus group. Insere o pesquisador como mediador do debate em que o tema foi a transferência dos residentes dos bairros-cota para o CDHU dando oportunidade de falarem suas impressões (Alves, 1999 e Alves \& Da Silva, 1992). Aplicou-se um questionário e depoimentos gravados às famílias dos BairrosCota sobre aspectos sociais da transferência para o CDHU e do novo local de moradia e seus impactos nas suas vidas, e a regeneração ambiental das áreas.

\section{Resultados e Discussão}

Os bairros-cota da Serra do Mar em Cubatão degradaram o meio ambiente e acarretaram um problema social grave para toda região da Baixada Santista, Figura 1.

Figura 1 - Exemplos de moradias antes do início do projeto.
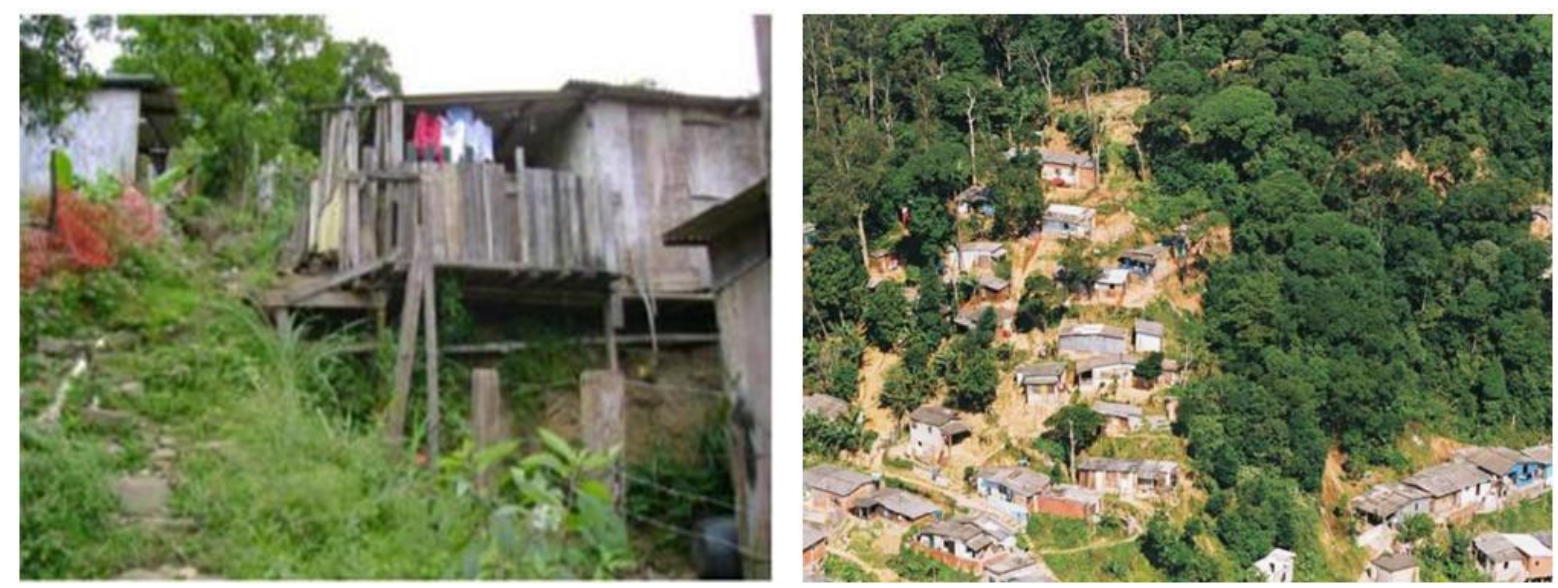

Fonte: https://www.infraestruturameioambiente.sp.gov.br 
Verifica-se, nas duas figuras, a ocupação desordenada da Serra do Mar com barracos à esquerda e residências desordenadas sem esgoto invadindo a área de vegetação. Vários foram os problemas decorrentes da ocupação desarmônica do Ecossistema, entre eles: destruição da Mata Atlântica com a construção de moradias de risco (ambiental), poluição do Rio Cubatão por falta de saneamento básico e esgoto a céu aberto (Economia Verde), precariedade no atendimento à saúde e educação da população na área degradada (social), local de abrigo de marginais para tráfico de drogas e assaltos aos transeuntes das estradas que passam na Serra do Mar (social), poluição ambiental da biodiversidade local pelo trânsito de caminhões, ônibus e veículos de motor de combustão (ambiental, social e econômico). Após várias discussões na Câmara de Vereadores de Cubatão com a presença de representantes dos Bairros-Cota, do Ministério Público, das Organizações Não-Governamentais e de Associações, e do Governo do Estado de São Paulo (stakeholders), resolveu-se construir um Projeto de Recuperação Socioambiental.

A partir do ano de 2007, o município de Cubatão colocou em prática o projeto de Recuperação Socioambiental da Serra do Mar. Inicialmente, várias famílias dos Bairros-Cota foram transferidas para o CDHU no Jardim Casqueiro, Figura 2.

Figura 2 - Conjunto habitacional Rubens Lara - Jardim Casqueiro.

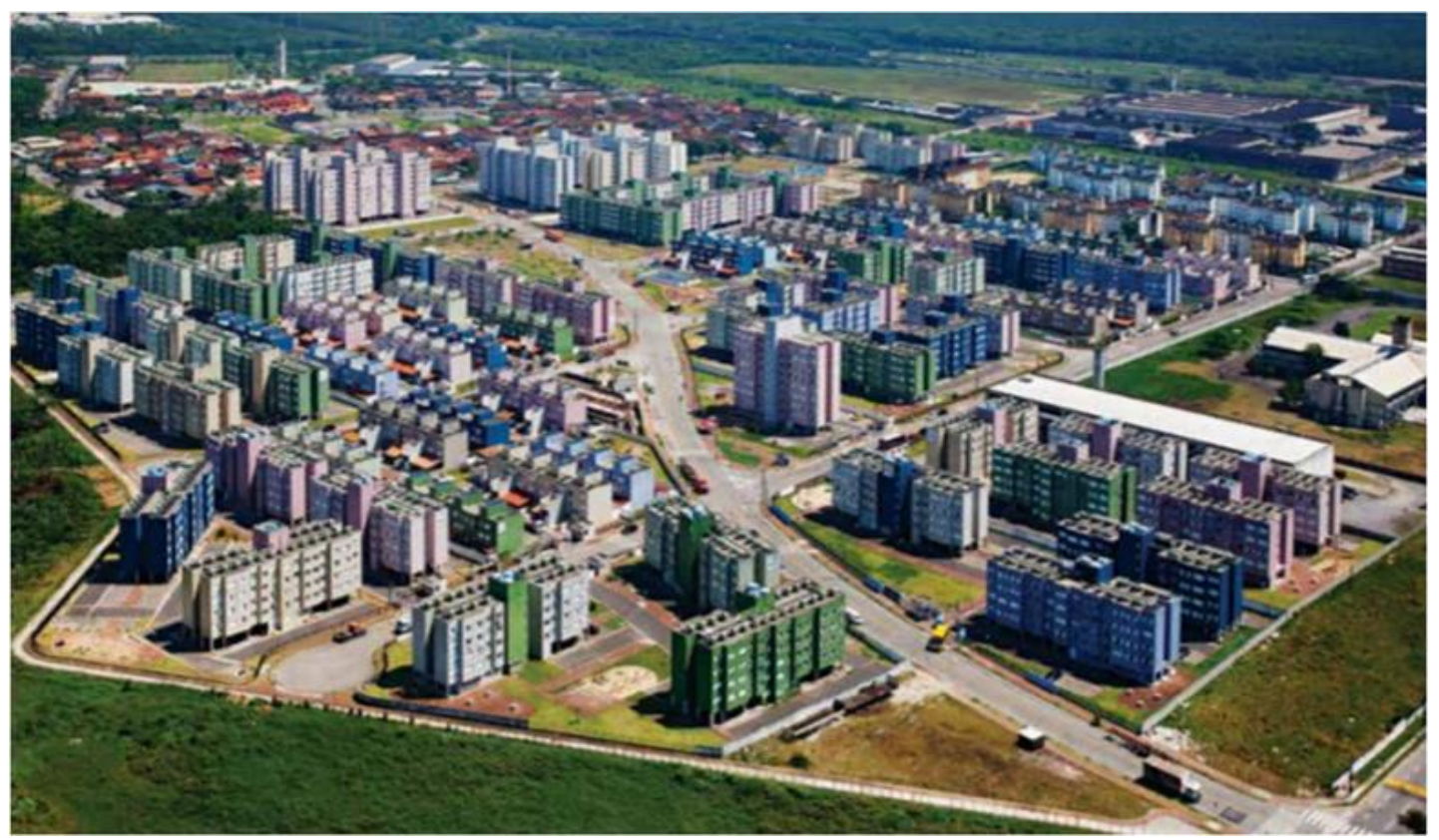

Fonte: https://www.infraestruturameioambiente.sp.gov.br

De um total de 7.824 edificações cadastradas, 5.318 foram removidas. O núcleo mais impactado com tais remoções foi o da Cota 200. As famílias envolvidas passaram de 
(CC BY 4.0) | ISSN 2525-3409 | DOI: http://dx.doi.org/10.33448/rsd-v9i7.4214

moradores de áreas invadidas, Bairros-Cota, à condição de residentes no Jardim Casqueiro, bairro com água encanada, esgoto, escola, supermercado, ônibus e unidade básica de saúde, isto é, toda infraestrutura mínima para socialização das pessoas, entretanto isso implica em deveres sociais a essas pessoas como responsabilidades financeiras, pagamentos de água e esgoto, energia elétrica, internet e IPTU, antes não existentes. O processo tem ocorrido de forma lenta, mas contínua. Ele tem sofrido ataques de pessoas que não possuem interesse em sair do local por inúmeros motivos, que vão desde não desejar pagar IPTU, água e esgoto, energia elétrica, internet até manter-se na clandestinidade, resultado evidenciado nos questionários e depoimentos.

A retirada das pessoas da Serra do Mar da Cota 400, gradualmente, contribuiu para a recuperação do meio ambiente, conforme a Figura 3.

Figura 3 - Cota 400 em 2012.

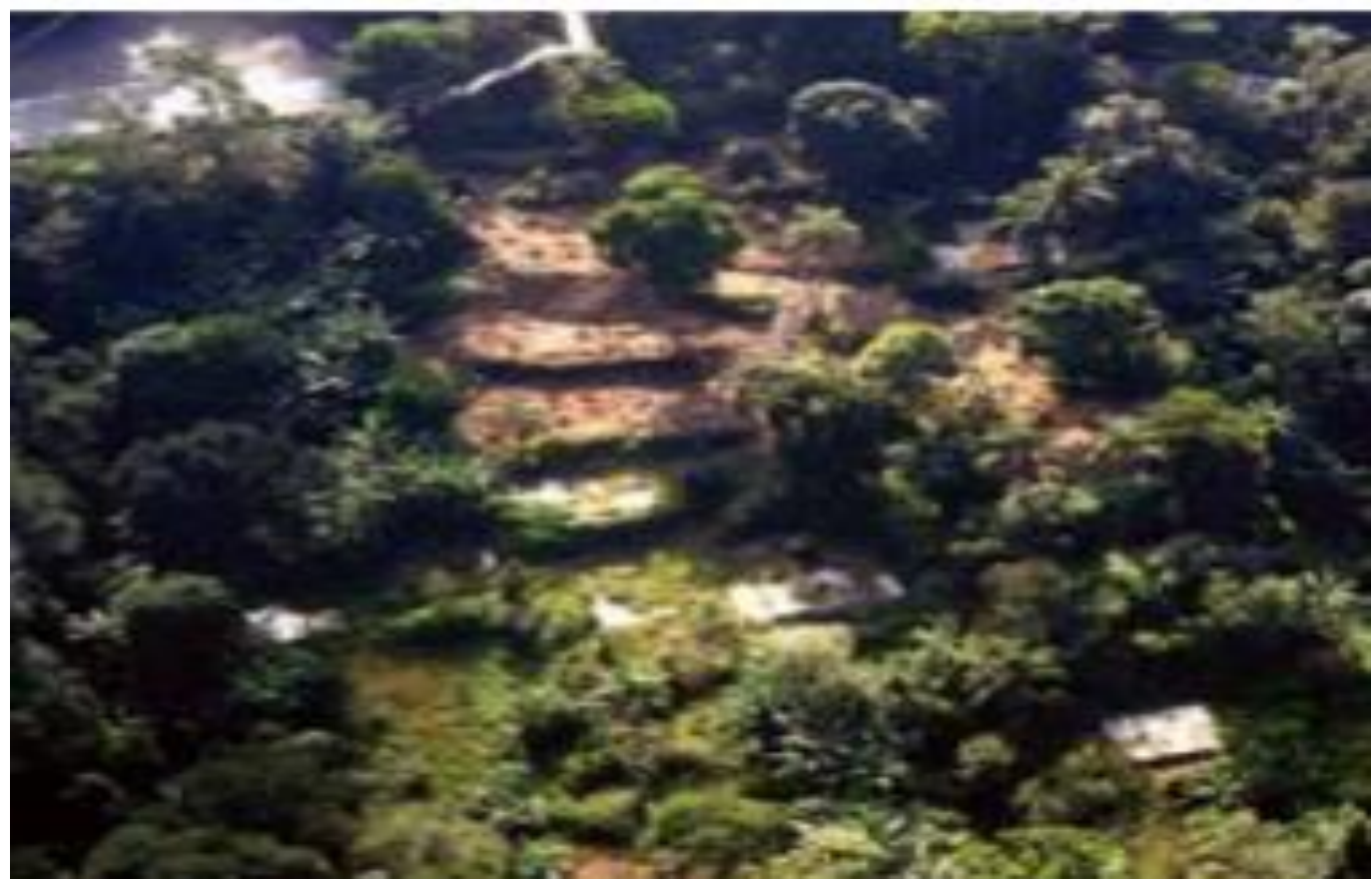

Fonte: https://www.infraestruturameioambiente.sp.gov.br/

Na Figura 3, verifica-se que a Mata Atlântica vai recuperando seu espaço perdido, após a retirada das moradias.

Na Figura 4, já se vê o avanço da regeneração vegetativa na Cota 400. Esse processo deve-se à ocupação da área pela Mata Atlântica, assim, melhorando o meio ambiente, além de diminuir a poluição ambiental e sonora, recuperando a biodiversidade. 
Research, Society and Development, v. 9, n. 7, e459974214, 2020

(CC BY 4.0) | ISSN 2525-3409 | DOI: http://dx.doi.org/10.33448/rsd-v9i7.4214

Figura 4 - Cota 400 em 2014.

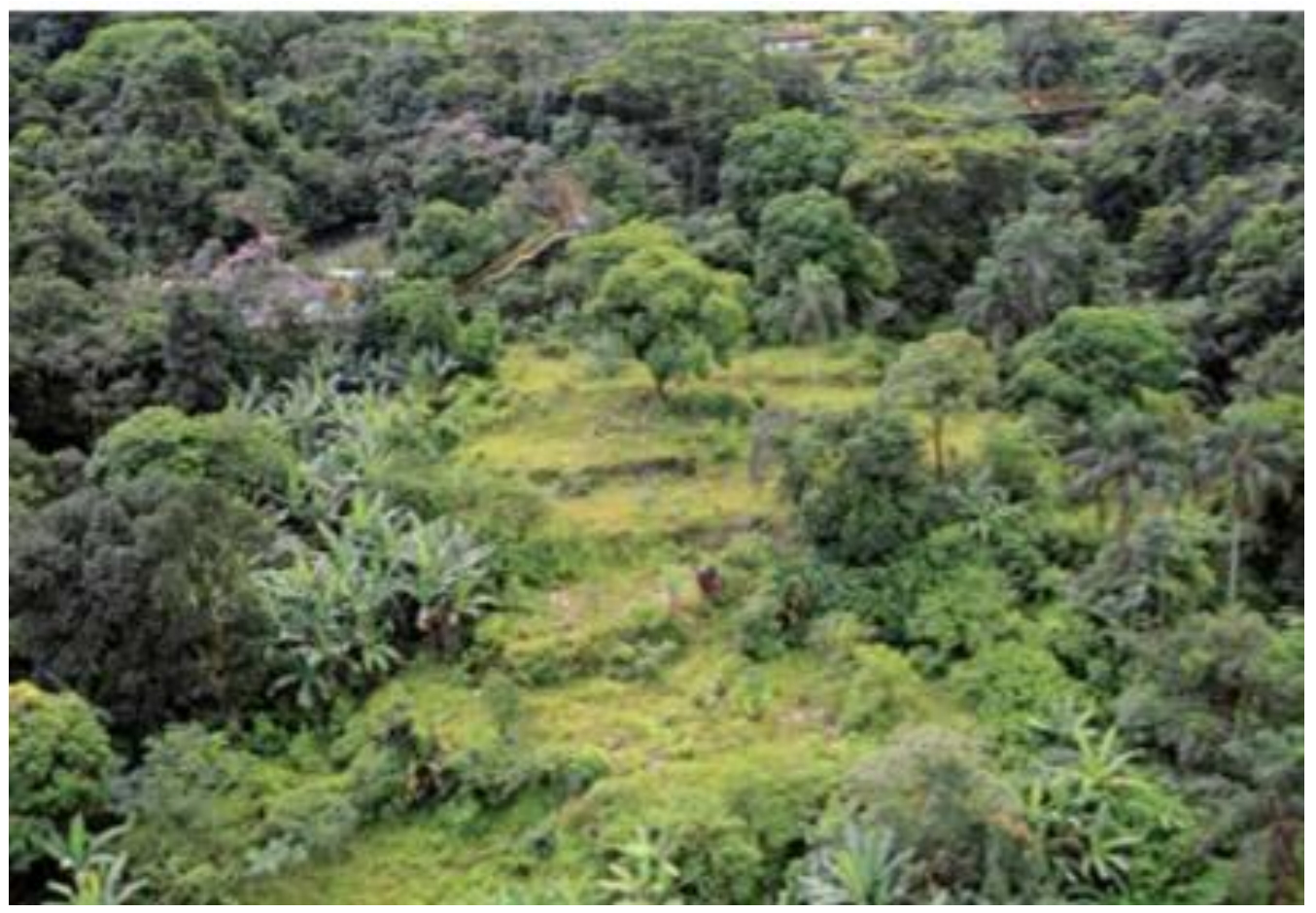

Fonte: https://www.infraestruturameioambiente.sp.gov.br

Já em relação a Cota 200, o processo é mais lento, devido a população local não aceitar o processo de mudança para o CDHU, conforme fatores citados acima. Essa dificuldade percebe-se na Figura 5.

Figura 5 - Cota 200 em 2009.

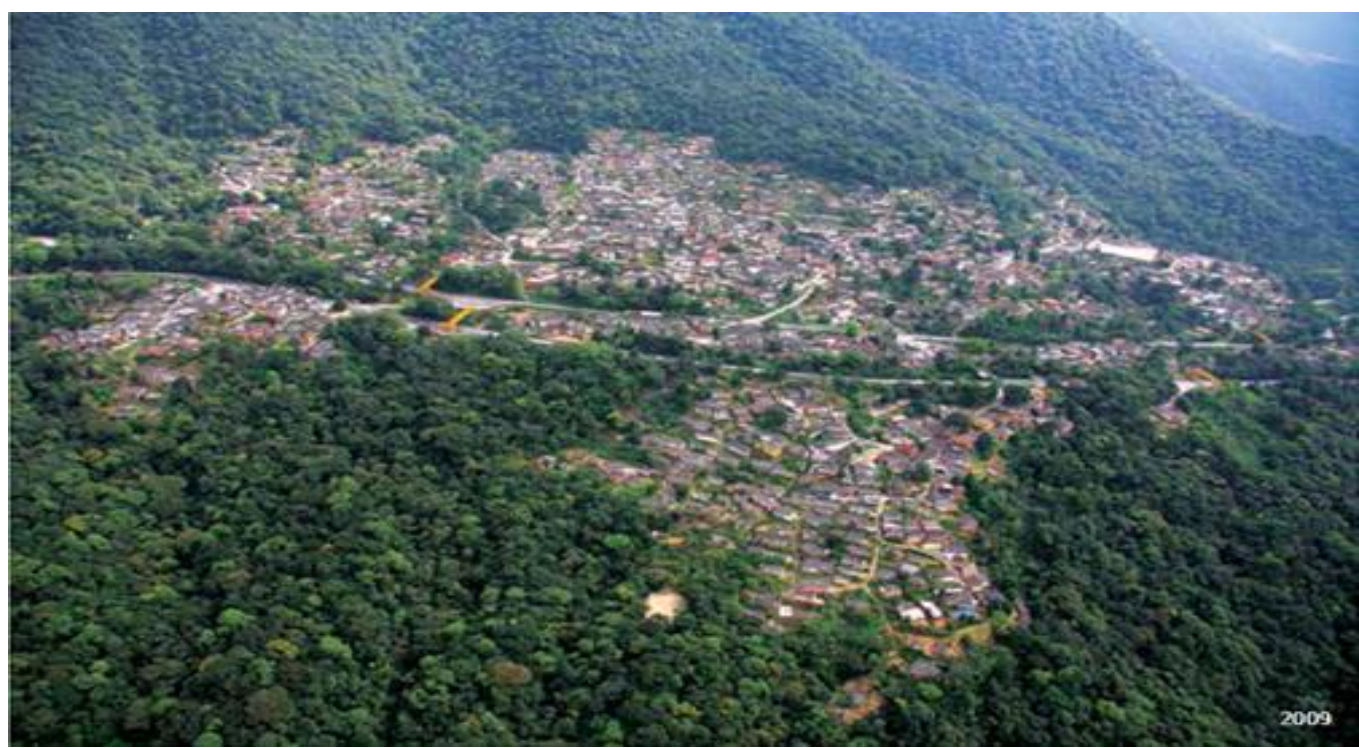

Fonte: https://www.infraestruturameioambiente.sp.gov.br/ 
(CC BY 4.0) | ISSN 2525-3409 | DOI: http://dx.doi.org/10.33448/rsd-v9i7.4214

A foto, obtida em 2009, mostra que há ainda centenas de moradias desordenadas sem esgoto e destruindo a biodiversidade, sem cobertura vegetal.

A Figura 6 é uma foto retirada do Google Earth atualizada que mostra ainda dificuldade na retirada dos moradores da Cota 200. Há vários fatores que incentivam a manutenção das famílias nessa área, entre eles não ter que pagar água, energia elétrica, internet (insumos) e IPTU, existir chefes de quadrilha que mantém tráfico de drogas, roubos aos veículos que passam nas rodovias e outras delinquências, possuir vereadores que têm suas bases eleitorais na região.

Figura 6 - Cota 200 em 2020.

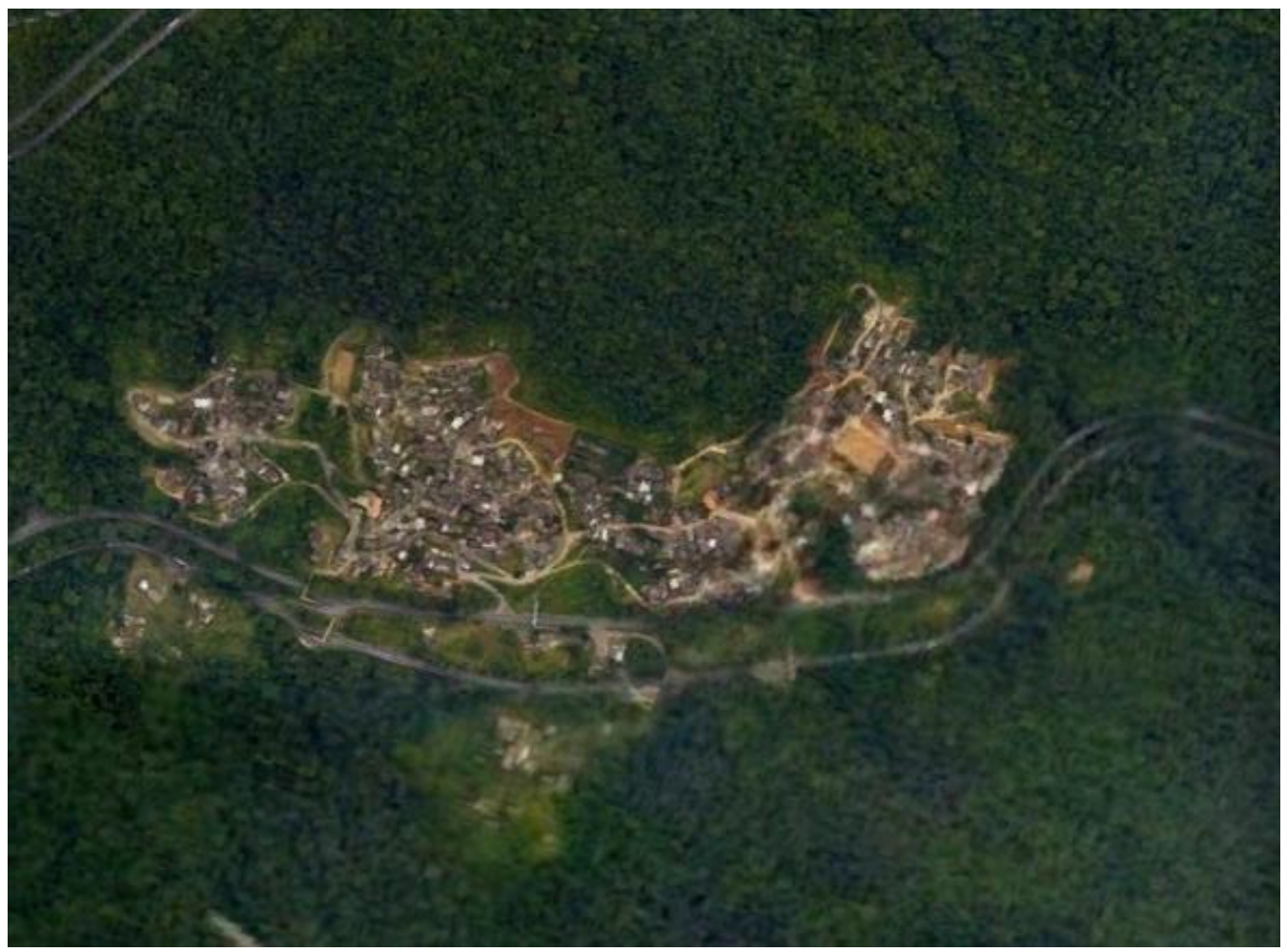

Fonte: Google Earth. Acesso em: 13 Mar 2020.

A questão ambiental tem uma complexidade ampla. Após o projeto de gestão múltipla de ações, observa-se que a ação dos agentes ambientais no replantio de mudas de plantas nativas e alto poder de regeneração da Mata Atlântica contribuem para que o local ocorra cobertura vegetal de forma constante e crescente.

Devido às condições geográficas do local que se trata de uma Serra, para evitar escorregamentos de terra, foram mantidas as lajes, após a retirada das moradias. Elas funcionam como barreiras de sustentação das encostas. Realizaram-se perfurações no concreto para o plantio de mudas, de forma que a própria vegetação se encarregue pelo 
(CC BY 4.0) | ISSN 2525-3409 | DOI: http://dx.doi.org/10.33448/rsd-v9i7.4214

rompimento delas. Com tudo isso, nota-se claramente a recuperação da Serra do Mar em Cubatão, Figura 7.

Figura 7 - Manancial presente na Serra do Mar.

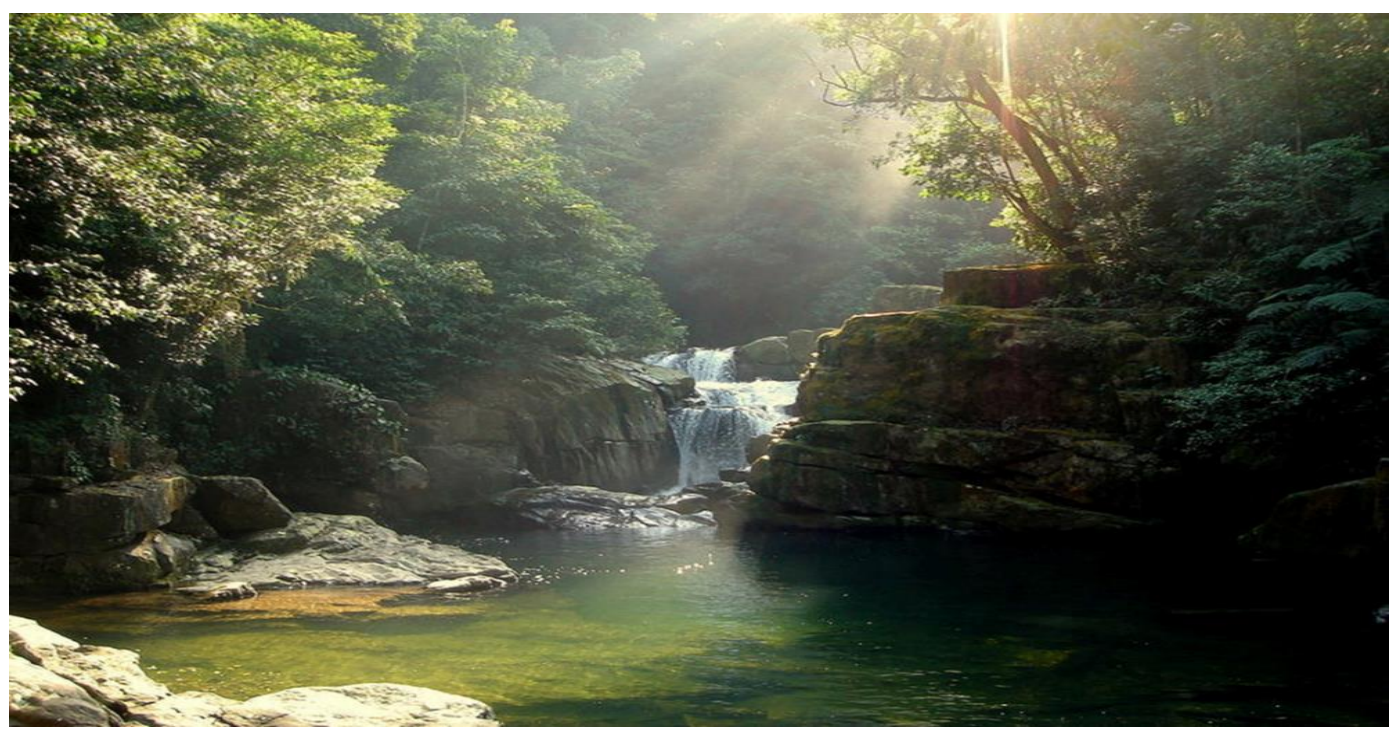

Fonte: https://www.infraestruturameioambiente.sp.gov.br

A Figura 7 mostra uma água límpida e intensa vegetação. A questão social abordada ocorreu através do questionário exploratório qualitativo e mesa de discussão. Os chefes de família, mulheres, informaram que a mudança foi excelente para $83 \%$, bom $10 \%$, regular $5 \%$ e ruim $2 \%$, após uma análise de conteúdo. Os $7 \%$ disseram ruim porque tem de arcar com IPTU, energia elétrica, água e internet.

\section{Considerações Finais}

O Projeto de Recuperação Socioambiental das áreas degradadas da Serra do Mar no município de Cubatão evidencia a aplicação prática da Gestão Social do Conhecimento e Economia Sustentável, desde sua elaboração à sua execução.

Transferiram-se as famílias que estavam em áreas de risco para bairro planejado no Jardim Casqueiro. Projetos sociais de capacitação e geração de renda foram implantados para recuperação socioeconômica dos moradores que permaneceram no local original, Cota 200, mas o correto seria a transferência de todas as famílias para a recuperação da biodiversidade original. 
Com a regularização fundiária e consolidação dos bairros, realizaram-se obras de infraestrutura básica, como construção de taludes para contenção de encostas, diminuindo os riscos de desabamento, pavimentação de ruas, fornecimento de água, energia elétrica e serviços básicos, como acesso à educação e saúde, Projeto Político Urbano. Implantaram-se Projetos de Educação Ambiental (Palma, Oliveira \& Losada, 2004).

Formaram-se agentes ambientais nas próprias comunidades de forma que eles participem diretamente no processo de plantio de mudas, promovendo mudanças de atitudes, conscientização e participação ativa que visam não só a recuperação como a preservação do meio ambiente.

No Turismo Local, é incentivado a construção de um Mirante na Cota 200, Economia Sustentável. Há necessidade de constante monitoramento do poder público e dos stakeholders para que não sejam criadas novas áreas de assentamentos irregulares, degradação ambiental. São organismos dinâmicos sujeitos às constantes mudanças.

A educação escolar local deve trabalhar alunos e pais para preservação e recuperação da biodiversidade. Um dos indicadores mostra o sucesso do projeto, monitoramento da área pelo Google Earth. Outro fator observado foi a qualidade da água do Rio Cubatão, verificando-se melhora na preservação das fontes d’água e água límpida.

A pesquisa tem pontos de continuidade, como investigar a influência da Covid-19 na baixada santista, inclusive cota 200, por meio da Gestão Social do Conhecimento e da Economia Sustentável e analisar qualidade da água do Rio Cubatão, desde a fonte, passando pelo uso e descarte no mar por meio do espectrofotômetro Raman.

\section{Referências}

Almeida, DS. (2016). Recuperação ambiental da mata atlântica. 3.ed. rev. e ampl. - Ilhéus : Editus, 2016. ISBN: 978-85-7455-406-8. Disponível em: 〈https://books.google.com. br〉. Acesso em: 23 Mar 2020.

Alves, HPF. (2013) Análise da vulnerabilidade socioambiental em Cubatão-SP por meio da integração de dados sociodemográficos e ambientais em escala intraurbana. R. bras. Est. Pop., Rio de Janeiro, 30(2): 349-66, jul./dez. 2013. Disponível em:

<http://www.scielo.br/pdf/rbepop/v30n2/02.pdf>. Acesso: 24 Mar 2020. 
Alves, PB et al. (1999). A construção de uma metodologia observacional para o estudo de crianças em situação de rua: criando um manual de codificação de atividades cotidianas. Estudos de Psicologia, 4(2): 289-310.

Alves, ZMMB \& Silva, MHGFD. (1992) Análise qualitativa de dados de entrevista: uma proposta. Scielo, Paidéia, no 2, Feb/July.

Brasil. (2020). Mata Atlântica. Ministério do Meio Ambiente. Disponível em: <https://www. mma.gov.br/biomas/mata-atlântica_emdesenvolvimento>. Acesso em: 23 Mar 2020.

Brasil. (2012). Código Florestal - Lei $n^{o}$ 12.651/2012. Disponível em: <http://www.planalto.gov.br/ ccivil_03/_Ato2011-2014/2012/Lei/L12651.htm>. Acesso em: 25 Mar 2020.

Brasil. (2008). Proteção da vegetação nativa do bioma mata atlantica - Decreto $n^{o}$ 6.660/2008. Disponível em: <https://legis.senado.leg.br/norma/410808>. Acesso em: 25 Mar 2020 .

Brasil. (2006). Bioma Mata Atlântica - Lei $n^{\circ}$ 11.428/2006. Disponível em: <http://www.planalto.gov.br/ccivil_03/_Ato2004-2006/2006/Lei/L11428.htm>. Acesso em 25 Mar 2020.

Brasil. (2000). SNUC - Lei $n^{o}$ 9.985/2000. Disponível em:

<http://www.planalto.gov.br/ccivil_03/LEIS/L9985.htm>. Acesso em: 24 Mar 2020.

Brasil. (1988). Constituição da República Federativa do Brasil. Disponível em: <http://www.planalto.gov.br/ccivil_03/Constituicao/Constituicao.htm>. Acesso em: 25 Mar 2020 .

Cantner, U, Joel, K \& Schmidt, T. (2011). The effects of knowledge management on innovative success - An empirical analysis of German firms. Research Policy - Elsevier, 40(1): 1453-62. 
Carayannis, EG. (1999) Fostering synergies between information technology and managerial and organizational cognition: the role of knowledge management. Technovation, 19(1): 21931.

D’Amato, D, Droste, N, Winkler, KJ \& Toppinen, A. (2019). Thinking green, circular or bio: Eliciting researchers' perspectives on sustainable economy with Q method. Journal of Cleaner Production - Elsevier, 230(1): 460-476.

Filippini, R, Güttel, WH \& Nosella, A. (2012). Ambidexterity and the evolution of knowledge management initiatives. Journal of Business Research - Elsevier, 65(1): 317-24.

Gerami, M. (2010) Knowledge Management. International Journal of Computer Science and Information Security, 7(2): 234-38.

CIESP. (2020). História do polo industrial em cubatão. Disponível em: <http://www. ciesp.com.br/cubatao/sobre/historia/>. Acesso em: 26 Mar 2020.

Luo, S-H \& Lee, G-G. (2013). Key factors for knowledge management implementation. Social Behavior and Personality, 41(3): 463-76.

Nowacki, R \& Bachnik, K. (2015) Innovations within knowledge management. Journal of Business Research-Elsevier, pp. 1-5.

Palma, CAP, Oliveira, CAS \& Losada, DR. (2004) Educação ambiental: abordagem pedagógica, social e econômica. Santos: Fundação Lusíada, v. 1. 329p.

Pereira, AS, Shitsuka, DM, Parreira, FJ \& Shitsuka, R. (2018). Metodologia da pesquisa científica. [e-book]. Santa Maria. Ed. UAB/NTE/UFSM. Disponível em: https://repositorio.ufsm.br/bitstream/handle/1/15824/Lic_Computacao_MetodologiaPesquisa-Cientifica.pdf?sequence $=1$.

Pirkkalainen, H \& Pawlowski, JM. (2014) Global social knowledge management Understanding barriers for global workers utilizing social software. Computer in Human Behavior-Elsevier, 30(1): 617-47. 
Rocha Neto, I. (2012) Gestão do Conhecimento e Complexidade. Revista de Gestão e Projetos, 3(1): 94-126.

Sadeghi, A. \& Rad, FM. (2018) The role of knowledge-oriented leadership in knowledge management and innovation. Management Science Letters, 8 (1): 151-60.

Souto Maior, MM \& Cândido, GA. (2014) Avaliação das Metodologias Brasileiras de vulnerabilidade socioambiental como decorrência da problemática urbana no Brasil. Cad. Metrop., São Paulo, 16(31): 241-64, jun 2014 http://dx.doi.org/10.1590/2236-9996.20143111. Acesso em: 28 Mar 2020.

\section{Porcentagem de contribuição de cada autor no manuscrito}

Cleia Aparecida Pinheiro Palma - 33,4\%

Roberto Pereira Borges - 33,3\%

Carlos Henriques Barroqueiro - 33,3\% 